\title{
European Union needs agro-bioeconomy ${ }^{\S}$
}

\author{
Tomasz Twardowski ${ }^{1 *}$, Alfredo Aguilar ${ }^{2}$, Pere Puigdomenech ${ }^{3}$, \\ ANNA LINKIEWICZ ${ }^{4}$, SŁaWOMIR SOWA ${ }^{4}$, TOMASZ ZIMNY ${ }^{5}$ \\ ${ }^{1}$ Institute of Bioorganic Chemistry, Polish Academy of Sciences, Poznań, Poland \\ ${ }^{2}$ European Federation of Biotechnology, Brussels, Belgium \\ ${ }^{3}$ Center for Research in Agricultural Genomics CSIC-IRTA-UAB-UB, Barcelona, Spain \\ ${ }^{4}$ GMO Controlling Laboratory, Plant Breeding and Acclimatization Institute - National Research Institute, Błonie, Radzików, Poland \\ ${ }^{5}$ Institute of Law Studies, Polish Academy of Sciences, Warszawa, Poland \\ ${ }^{\S}$ Opinion paper based on the session Bioeconomy in the EU without GMO \\ held during the $5^{\text {th }}$ Polish Congress of Genetics, Łódź, 19-22. 09. 2016
}

\begin{abstract}
Bioeconomy, biotechnology and genetically-modified organisms in particular have been the subject of discussion for a long time. Biotechnology is applied in a variety of economic areas which include biopharmaceuticals, biobased products and agriculture. During the last 20 years, innovative biotechnological techniques for plant genome improvement have been developed. Many factors worldwide have led to the status quo: different legislations around the world, the lack of public acceptance in the EU and high expectations for new strategies for sustainability and food security. Therefore, a clear regulatory status for new techniques is crucial for research and development, as well as for their practical implementation. This should be based on solid science which plays a critical role in developing the bioeconomy.
\end{abstract}

Key words: agrobiotechnology, bioeconomy, GMO, new plant breeding techniques

\section{Introduction}

In the European Union, the bioeconomy has its roots in the region's excellent level of basic scientific expertise and the successful integration of the life sciences, biotechnology, industry, and legal as well as social aspects of our everyday life. One aspect that is important to stress is the difference between the bioeconomy and genetically modified organisms (GMOs). Whilst the former is a socio-economic process involving policy makers, economists, civil society, agriculture, industry, technology (e.g. biotechnology), scientific disciplines (e.g. genetics), etc., the latter, i.e. GMOs, are products of some of the genetic engineering techniques used to modify the genetic material of living organisms. According to Directive 2001/18, GMOs are products of particular techniques only if the use of this technique leads to specific results (a change of the genetic material that goes be- yond the natural process of genetic modification, see chapter "changes in legislation"). Among GMOs, transgenic plants are a subset of the panoply of genetic enhancements introduced to produce bioproducts (e.g. insulin, growth hormones, proteases, etc.). However, for a successful bioeconomy it is essential that all existing technologies are made available, including, where appropriate, the use of GMOs. It would be unrealistic to think that the global challenges that the world is facing - food security, climate change, sustainability, etc., could be properly addressed if some of the technologies already available were stigmatized. Countries and regions following this approach will surely be left behind in the global competitive market, as other more innovationfriendly societies will develop a bioeconomy based on solid and factual science. The sustainable growth of the EU needs an innovative and science-based economy. 
This vision should be shared by enterpreneurs, investors, consumers and the public sector.

\section{New plant breeding techniques - real innovations for sustainable agriculture in the $\mathrm{EU}$}

Biotechnology plays an important role in the modernization of agriculture toward the generation sustainable fuel, food and feed production. European agriculture has to face new challenges related to the intensification of crop production in an environmentally-reasonable and economically-sustainable manner. Climate changes reduce soil fertility and increase water scarcity. The intensive use of pesticides and greenhouse gas emissions increase arable soil degradation. Finally, there is the need to produce more and more efficiently with fewer natural resources. This can be achieved through sustainable growth, but it requires the development of new green technologies which will help to build a low carbon economy, protect the environment and prevent losses of biodiversity. Plant breeding is a key element of crop productivity gains, but it requires continuous investment in research and the development of new cultivars. Therefore, life sciences and biotechnology have become an important part of the EU's strategy for innovation. Access to innovation, especially for small and mid-sized enterprises, has become crucial for reducing yield gaps observed in the EU. During the last 20 years, innovative biotechnological techniques, and especially new plant breeding techniques (NBTs), have been developed. NBTs are a set of various techniques used for plant genome improvement (cisgenesis, intragenesis, oligonucleotide-directed mutagenesis, RNA-dependent DNA methylation, reverse breeding, zinc finger nucleases, TALE nucleases, CRISPRCas9 system, etc.) (Lusser et al., 2012). These techniques of targeted genome modification enable researchers to modify genes of interest, to investigate their functions and explore their applications for the genetic improvement of plants. NBTs decrease the time and effort required to produce new plant varieties. Cisgenesis, for example, has great potential in breeding resistance. Unlike transgenesis, it utilizes only internal, native DNA elements (Holme et al., 2013). Importantly, the genes introduced in this way to a genome are regulated in the same way as in the plants which they come from. Cisgenesis has also been successfully applied to introduce resistance to the late blight caused by Phytophthora infestans, which is the most devastating disease in potato production fields (Haverkort et al., 2009). The traditional way of protecting potatoes against the late blight requires spraying 15 times with fungicides, which represents approximately $50 \%$ of all pesticides used in the Netherlands. Apple scab caused by the fungus Venturia inaequalis is the most serious disease affecting apple production in Europe. Cisgenesis has been used to accumulate resistance genes and introduce them into high quality apple cultivars (Joshi et al., 2009). In its scientific opinion, the European Food Safety Authority concluded that the varieties of the cisgenic plant are as safe as the varieties obtained through conventional breeding techniques (EFSA (2012)).

In some NBTs, recombinant DNA is introduced temporarily to the plant genome to induce permanent mutation in the integral gene sequence (TALEN, ZNF, CRISPR-Cas9). The use of site-specific nucleases (SSN) such as TALEN or CRISPR-Cas9 may introduce very precise site-specific mutations which can result in simultaneous editing of more than one allele in the polyploid species. An SSN-mediated mutation via TALEN has been used to knock-out the expression of the susceptibility of the mlo gene that is required for the infection process of Blumeria graminis f. sp. tritici (Bgt) cousing powdery mildew in wheat. Interestingly, using these techniques three homoeoalleles in hexaploid bread wheat have simultaneously been targeted in the same plant (Wang et al., 2014). The first product of CRISPRCas9 technology is already on the market: a white button mushroom (Agaricus bisporus) modified with the CRISPR-Cas9 technique to resist browning has been licensed for cultivation and sale in the USA.

On the other hand, reverse breeding only allows the introduction of temporal changes in the gene expression profiles. This approach leads to the production of plants with no change in the DNA sequence itself. When the steps of selection and breeding are followed, the final varieties are not essentially different from what could have been obtained by traditional methods.

\section{Examples of genomic approaches for plant bre- eding. The case of Cucurbitaceae}

Plant breeding became a scientific discipline when genetics developed as a science at the beginning of the last century. It is well known that Gregor Mendel carried out some of his essential work on plants such as peas. Nevertheless, some of the basic concepts of genetics 
were coined before Mendel and some of these were arrived at in plant families such as Cucurbitaceae (cucurbits). The best example of this is possibly the work of Augustin Sageret who, in 1826 (Sageret, 1826), defined the concept of character when describing inheritance in melon. Cucurbitaceae have continued to serve as a model analyzed for important genetic traits in plants. A good example is the analysis of sex determination in plants that has recently been reported (Martin et al., 2009; Boualem et al., 2015). From a molecular point of view, cucurbits display a number of interesting features. They are diploid and have not undergone recent whole genome duplications. Moreover, they have relatively compact genomes (between 300 and $450 \mathrm{Mb}$ ). These features make it possible to develop projects to obtain whole genome sequences from these species. This has been done in recent years, as a result of the economic interest in these species. In economic terms, cucurbits are the most important horticultural species worldwide after Solanace. They contribute to the human diet on all continents and industrial interest in their seeds is very significant.

Among Cucurbit species, melon (Cucumis melo) is of special interest in Spain, where it has traditionally been an important crop in some regions. Therefore, it was decided to undertake a project to obtain its whole genome sequence and to develop genomic tools that could be useful for the study of its biology and for the breeding of the species. The project was carried out on a double haploid line from a cross between two distant varieties in order to facilitate the assembly of the genome and to start obtaining information about genome variability. The method used was massive DNA sequencing together with BAC-end sequencing in order to improve the quality of the final sequence. The sequence was published in 2012 (Garcia-Mas et al., 2015) and other genome sequences from the Cucurbitaceae family have been published as well. The first of these was the genome from cucumber (Huang et al., 2009) that has been completed with a number of accessions from the same species (Guo et al., 2013) and the genome of watermelon. Comparative studies between these species have been done, in particular in regions rich in sequences with similarity to resistance genes (González et al., 2014). One of the interesting elements of these projects is the anchoring of the sequences to the genetic map, which is becoming an important tool for breeders.
It is interesting to note that a genetically modified melon variety was among the events that were submitted according to Directive 90/22/EC and approved in 1990. This was a virus resistant variety that has not subsequently been commercialized. The control of ripening in melon was yet another interesting project (Ayub et al., 1996); also not commercialized, due to the high cost imposed by existing regulations concerning GMOs. It has been shown that genome editing using CRISPR/Cas9 methods works in cucurbits and that new resistance against pathogens can be produced in this way (Chandrasekaran et al., 2016). The use of new plants created using NBTs that many experts consider non-GMOs, because they do not contain any foreign insertion, will depend on decisions on the regulatory status of the plants obtained by these new technologies [see the next section of this paper].

\section{Changes in GMO legislation}

The recent changes to EU legislation regulating the use of GMOs seem quite restrictive for large scale adoption of genetic engineering as a technology. These changes pertain, in particular, to growing geneticallymodified plants, which can be banned by the Member States of the European Union, even though such plants have been duly authorized for this purpose according to EU law ${ }^{1}$. Since such bans have been introduced by a majority of the Member States (EU, 2016a) and only one such plant has been authorized for growing anyway (MON 810 corn), it does not seem likely or even seem reasonable that entrepreneurs from the biotechnology sector would invest in breeding of genetically-modified varieties designed for the European market. Despite their use in medicine and even agriculture (mostly as animal feed) and despite the fact that many GMOs have been authorized as food products in the $\mathrm{EU}^{2}$ (EU, 2016b), GMOs are generally shunned as food and growing material in the region. Since genetic engineering is only one of the tools used in plant breeding, breeders might seek to adopt alternatives in order to develop new solutions for the seed sector, in particular for $\mathrm{NBTs}^{3}$.

\footnotetext{
${ }^{1}$ See Directive 2015/412/EU amending Directive 2001/18/EC as regards the possibility for Member States to restrict or prohibit the cultivation of genetically-modified organisms (GMOs) in their territory.

${ }^{2}$ http://ec.europa.eu/food/dyna/gm_register/index_en.cfm

${ }^{3}$ See above.
} 
Practical application of NBTs into breeding depends on their legal classification, as some of these include genetic engineering. The classification of a product resulting from NBTs as a GMO would lead to limited use of these techniques in breeding, because of the very high cost of GMO authorization in the EU. Another barrier is obligatory labeling and low public acceptance of GM food in the EU. The current definition of a GMO in EU legislation is over 25 years old and there is urgent need for updating GMO legal texts to reflect recent developments. This, however, requires a clear harmonized system of GMO classification in order to ensure trade in agricultural products as well as the motivation of EU Member States to accept this kind of innovation in European agriculture. The status of such techniques from the point of view of GMO legislation seems doubtful, however. The legislation regulating the use of GMOs in the European Union imposes severe restrictions on the widespread use of organisms obtained by techniques that meet the definition set forth in Directive 2001/ $18 / \mathrm{EC}^{4}$. This definition (as cited below) is subject to several exceptions (with mutagenesis being the most prominent) and is thus vague in itself. This results in confusion as to whether particular organisms obtained

4 "genetically modified organism (GMO)" means an organism, with the exception of human beings, in which the genetic material has been altered in a way that does not occur naturally by mating and/or natural recombination;

Within the terms of this definition:

a) genetic modification occurs at least through the use of the techniques listed in Annex I A, part 1:

1) recombinant nucleic acid techniques involving the formation of new combinations of genetic material by the insertion of nucleic acid molecules produced by whatever means outside an organism, into any virus, bacterial plasmid or other vector system and their incorporation into a host organism in which they do not naturally occur but in which they are capable of continued propagation;

2) techniques involving the direct introduction into an organism of heritable material prepared outside the organism including micro-injection, macro-injection and micro-encapsulation;

3) cell fusion (including protoplast fusion) or hybridization techniques where live cells with new combinations of heritable genetic material are formed through the fusion of two or more cells by means of methods that do not occur naturally.

b) the techniques listed in Annex I A, part 2, are not considered to result in genetic modification:

Techniques referred to in Article 2(2)(b) which are not considered to result in genetic modification, on condition that they do not involve the use of recombinant nucleic acid molecules or genetically modified organisms made by techniques/methods other than those excluded by Annex I B:

1) in vitro fertilization,

2) natural processes such as: conjugation, transduction, transformation,

3) polyploidy induction. with the use of certain NBTs are going to be considered GMOs or not. For instance, while the European Food Safety Authority (EFSA) passed an opinion that similar hazards can be associated with cisgenic and conventionally-bred plants (EFSA, 2012), cisgenic plants seem to meet the GMO definition and are still subjected to GMO authorization procedures. Recently, the Swedish Board of Agriculture confirmed that plants in which the genome has been edited using the CRISPR-Cas9 technology do not fall within the European GMO definition (CRISPR-muterad backtrav (2015)). On the other hand as of the date of writing this article, the European Commission has failed to deliver an opinion as to whether organisms obtained through CRISPR/Cas9 are to be considered GMOs or not. This situation has led to a sense of uncertainty when it comes to the techniques entrepreneurs and farmers can invest in. Considering the length of the breeding process and the uncertainty as to whether products are going to be at all marketable in the EU, this situation can have a detrimental effect on the seed sector and economy as such, given that the EU is the world's second biggest seed exporter with a reproductive material market of around $€ 6.8$ billion (Laaninen, 2016).

The regulatory status of NBTs is crucial for implementing innovations into the European plant breeding industry. It is also important for research and development in the life sciences, as the contained use and deliberate release of GMOs into the environment are regulated in the EU. We are of the opinion that each of the NBTs should be assessed individually on a "case by case" basis, taking into account both the technology and the end-product. Another remedy (from the point of view of the certainty of law) would be an amendment to the GMO definition in the legislation, but this could not be achieved within a short time frame, as it would require a multi-partially-agreed position to be adopted by the Member States. The European Commission will need to provide legal certainty very soon, which could be done by appropriate interpretation of the GMO definition in Directive 2001/18/EC rather than changing the Directive itself.

If particular NBTs are outside the GMO legislation, it will be of clear benefit for society. EU farmers would be able to get access to the best varieties; and breeding companies and the whole EU seed industry would consequently remain competitive. European citizens will benefit from safer food and a clean environment. We can 
expect that research into and development of innovative technologies will be conducted in Europe. Last but not least, it will be a benefit for the European Commission and the governments of the EU Member States - a way out of the GM impasse toward sustainable agriculture.

\section{Patent law is critical for the biotech sector}

Another area that could influence the European biotech sector are the recent developments in patent law. With the US Supreme Court Judgments in the case $M y$ riad Genetics ${ }^{5}$ that deem DNA sequences as they occur in nature not patentable, a major shift in biotech companies' policies can be expected. Although such techniques are still patentable in Europe ${ }^{6}$, it is possible that globally companies will move toward treating their data on sequences as trade secrets rather than patenting them (Conley et al., 2014). Also, while plant varieties are generally considered not patentable ${ }^{7}$, such a ban could be circumvented by showing that a particular invention can be used in a broader taxon than a variety (Bostyn, 2013). Furthermore, after the European Patent Office's decision in the cases of Broccoli/Tomato II $^{8}$, although conventional breeding processes cannot be patented, as they are deemed "essentially biological", products of such processes (i.e. plants and their parts) can be patented. The present situation seems rather confusing and begs the question as to the consistency of the patent system as such. It also influences breeders' rights, their choices and strategies, since the breeder's exception is not consistently present across patent legislations (Prifti, 2015).

It is currently too early to predict the large-scale effects of the present developments and problems on the European bioeconomy; however, it seems clear that the sector is currently at a crossroads, with difficult decisions to be made for the future, in particular by policymakers.

\section{Conclusions}

The European Union and many countries in Europe and worldwide have developed a number of different strategies for the bioeconomy, many of them focused on

\footnotetext{
${ }^{5}$ Association for Molecular Pathology v. Myriad Genetics, No. 12398, 569 U.S. June 13, 2013.

${ }^{6}$ Art. 3.2 of Directive $98 / 44 /$ EC On the protection of biotechnological inventions.

${ }^{7}$ Art. 4.1 of Directive 98/44/EC.

${ }^{8}$ Cases G 2/12 and G 2/13.
}

the development of a sustainable and economically-viable agroindustry. There is no one bioeconomy, but many bioeconomies that need to take into account climate, agricultural conditions, rural and socio-economic environments, etc. Therefore, each country must identify their own priorities and objectives. However, there are a number of elements that all bioeconomies must have in common: solid, technology-based science, a positive socioeconomic environment, a coherent legal framework, and an overall agreement that sustainability and food security are critical for any development.

An innovative and sustainable bioeconomy is key to guarantee the prosperity of future generations. Scientists and also policy makers have a joint responsibility to ensure that "global challenges" such as food security on a global level, the impact of climate change on agriculture, the desertification or salinization of our soils, etc. are properly translated into concrete actions. Solutions must be found at the local or regional level, but these challenges are global for mankind as a whole. Europe has, over the last centuries, been the cradle of rationalism and scientific endeavor and this is critical to mankind: progress based on science and on technology. It is also important to realize that an apparently minor decision taken in Europe to ban the use of GMOs may have a lasting and a profound negative impact on developing countries. The most important pillar of bioeconomy and its intrinsic component is that it must be science-based. Banning the use of GMOs for non-scientific reasons makes the development of a long-term sustainable bioeconomy impossible.

\section{Acknowledgements}

This paper was partially supported by both the Polish Ministry of Science and Higher Education within the KNOW program and a grant for young scholars as well as the Polish Ministry of Agriculture and Rural Development within the multiannual program 2015-2020.

\section{References}

Ayub R., Guis M., Ben Amor M., Gillot L., Roustan J.P., Latché A., Bouzayen M., Pech J.C. (1996) Expression of ACC oxidase antisense gene inhibits ripening of cantaloupe melon fruits. Nat. Biotechnol. 14: 862-866.

Association for Molecular Pathology v. Myriad Genetics, No. 12-398, 569 U.S. June 13, 2013.

Bostyn S. (2013) Patentability of plants: at the crossroads between monopolizing nature and protecting technological innovation? J. World Intel. Property 16(3-4): 105-149. 
Boualem A., Troadec C., Camps C., Lemhemdi A., Morin H., Sari M.A., Fraenkel-Zagouri R., Kovalski I., Dogimont C., Perl-Treves R., Bendahmane A. (2015) A cucurbit androecy gene reveals how unisexual flowers develop and dioecy emerges. Science. 350: 688-691.

Chandrasekaran J., Brumin M., Wolf D., Leibman D., Klap C., Pearlsman M., Sherman A., Arazi T., Gal-On A.. (2016) Development of broad virus resistance in non-transgenic cucumber using CRISPR/Cas9 technology. Mol. Plant Pathol. 17: 1140-1153.

Conley J.M., Cook-Deegan R., Lazaro-Munoz G. (2014) Myriad after Myriad: the proprietary data dilemma. North Carolina J. Law Technol. 15(4): 597-637.

CRISPR-muterad backtrav (2015) http://www.umu.se/digital Assets/171/171718_beslut-umea.pdf.

EFSA (2012) Scientific opinion addressing the safety assessment of plants developed through cisgenesis and intragenesis. EFSAJ. 10(2): 2561 (http://www.efsa.europa.eu/ en/efsajournal/pub/2561).

Garcia-Mas J., Benjak A., Sanseverino W., Bourgeois M., Mir G., González V.M., Hénaff E., Câmara F., Cozzuto L., Lowy E., Alioto T., Capella-Guitérrez S., Blanca J, Cañizares J., Ziarsolo P., Gonzalez-Ibeas D., Rodríguez-Moreno L., Droege M., Du L., Alvarez-Tejado M., Lorente-Galdós B., Melé M., Yang L., Weng Y., Navarro A., MarquesBonet T., Aranda M.A., Nuez F., Picó B., Gabaldón T. et al. (2012): The genome of melon (Cucumis melo L.). PNAS 109: 11872-11877.

Guo S., Zhang J., Sun H., Salse J., Lucas W.J., Zhang H., Zheng Y., Mao L., Ren Y., Wang Z. et al. (2013) The draft genome of watermelon (Citrullus lanatus) and resequencing of 20 diverse accessions. Nature Genet. 45: 51-58.

González V.M., Aventín N., Centeno E., Puigdomènech P. (2014) Interspecific and intraspecific gene variability in a 1-Mb region containing the highest density of NBS-LRR genes found in the melon genome. BMC Genom. 15: 1131.

Haverkort A.J., Struik P.C., Visser R.G.F., Jacobsen E. (2009) Applied biotechnology to combat late blight in potato caused by Phytophthora infestans. Potato Res. 52: 249-264.
Holme I.B., Wendt T., Holm P.B. (2013) Intragenesis and cisgenesis as alternatives to transgenic crop development. Plant Biotechnol J. 11(4): 395-407.

Huang S., Li, R., Zhang Z., Li L, Gu X., Fan W., Lucas W.J., Wang X., Xie B., Ni P., Ren Y. et al. (2009) The genome of the cucumber, Cucumis sativus L. Nature Genet. 41: 1275-1281.

Joshi S.G., Soriano J.M., Kortstee A., Schaart J.G. (2009). Development of cisgenic apples with durable resistance to apple scab. Acta Horticult. 839: 403-406.

Laaninen T. (2016) New plant-breeding techniques. Applicability of GM rules, EU 2016.

Lusser M., Parisi C., Plan D., Rodriguez-Cerezo E. (2011) New plant breeding techniques. State-of-the-art and prospects for commercial development. Rep. EUR 24760 EN. European Commission - Joint Research Centre, Institute for Prospective Technological Studies.

Prifti V. (2015) The Breeder's Exception to Patent Rights Analysis of Compliance with Article 30 of the TRIPS Agreement. Springer 2015: 176.

Restrictions of geographical scope of GMO applications/authorisations: Member States demands and outcomes (2016a) http://ec.europa.eu/food/plant/gmo/authorisation/cultiv ation/geographical_scope_en.htm

EU Register of authorised GMOs (2016b) http://ec.europa.eu/ food/dyna/gm_register/index_en.cfm

Martin A., Troadec C., Boualem A., Rajab M., Fernandez R., Morin H., Pitrat M., Dogimont C., Bendahmane A. (2009) A transposon-induced epigenetic change leads to sex determination in melon. Nature 461: 1135-1138.

Sageret A. (1826) Considérations sur la production des Hybrides, des variantes et de Variétés en géneral et sur celles de la famille des Cucubitacées en particulier. Annal. Sci. Naturel. 8: 294-314.

Wang Y., Cheng X., Shan Q., Zhang Y., Liu J., Gao C., Qiu J-L. (2014) Simultaneous editing of three homoeoalleles in hexaploid bread wheat confers heritable resistance to powdery mildew. Nat. Biotechnol. 32(9): 947-951. 